\section{OMT training key to profession}

\section{To the Editor:}

The case report by Drs Pintal and Kurtz, "An integrated osteopathic treatment approach in acute otitis media," (JAOA $1989 ; 89: 1139-1141)$ gives me new hope for the future of the osteopathic medical profession.

Dr Pintal's expert description of the osteopathic manipulative treatment (OMT) used to facilitate healing the patient with acute otitis media should be required reading for all general practitioners and otorhinolaryngology residents. If more of our resident specialty trainers understood, practiced, and taught some of these simple OMT approaches, we would eventually need no specialty departments of osteopathic manipulative medicine in our colleges. Our patients, who benefit from OMT, would soon tell the world what distinguishes osteopathic medical physicians from other healthcare professionals.

V.C. HOEFNER, Jr, DO

Associate Professor

Department of Osteopathic Manipulative Medicine

Kirksville College of Osteopathic Medicine

Kirksville, Mo

\section{Research: The future begins today}

\section{To the Editor:}

In the article "Incidence of spinal palpatory findings: A re- view," (JAOA 989;89:10271030,1033-1035) Myron C. Beal, DO, attempts to summarize the published epidemiologic data on spinal somatic dysfunction. Although the reviewed studies represent our profession's beginning attempts to define somatic dysfunction in populations, much work lies ahead to establish highquality epidemiologic research.

Only when we have laid the ground work for such research can we begin to objectively answer fundamental questions surrounding osteopathic principles, which we have clinically practiced for years. Among the missing data are prevalence and incidence rates of somatic dysfunction in the population-at-large, not to mention more difficult and complicated analytic and experimental research.

Before undertaking such endeavors, the profession must cultivate an interest and commitment to research. This means dedicating time, personnel, and resources. Specifically, individuals trained in epidemiologic and biostatistic methods are needed, as is a "population" laboratory where random probability samples can be acquired and somatic dysfunction can be objectively analyzed.

While financial support will determine the realization of these goals, no price tag can be put on the value of research to our profession. Without it, our scientific foundation will deteriorate. With it, much new knowledge will be gained and the profession will be strengthened. The fate of the osteopathic medical profession rests in our hands. We must decide the future now.
STEVEN J. BOWLIN, DO

The Research Institute of The Mary

Imogene Bassett Hospital

Cooperstown, NY

\section{Canada calling DOs}

\section{To the Editor:}

For the past 58 years in which I have been a practicing DO, I have been trying in vain to find osteopathic physicians who would locate to Saskatchewan to practice OMT. My late partner, Anna Northup Little, DO, had been working diligently to attract DOs to Saskatchewan for 15 years before I came here. We continued to work together in this effort for 46 years until Dr Little died. During all that time, we had not been able to attract a single osteopathic physician who would stay for more than a few months. This leads me to the conclusion that few graduates are interested in the practice of OMT. Surely something can be done to alter this situation.

I have successfully treated many patients with many types of conditions using OMT, albeit with less strenuous techniques of late. I have yet to find any great need to prescribe drugs for my patients except in emergency cases.

Patients are seeking alternate healthcare methods as they report feeling better without drug therapy. My waiting list rarely numbered fewer than 150 patients when I was practicing fulltime. Unfortunately, my age, 91 years old, and arthritis now limit me from seeing more than three 
letters

(continued)

patients each day. I accept only patients who have not received help from other forms of therapy. If DOs really understand osteopathic principles and practices, they would realize that OMT deals with causes rather than symptoms. As such, it offers longlasting benefits without adverse side effects. Furthermore, OMT does more than help lame backs and stiff necks as many osteopathic physicians seem to believe.

Realizing that I shall not be practicing much longer, my patients are greatly concerned about their future healthcare; no other DO can be found in the entire province of Saskatchewan. Any osteopathic physician willing to use OMT could have an instant practice here, and more important, a host of grateful patients.

DORIS M. TANNER, DO

Regina, Saskatchewan

\section{Coming in ...}

\section{THE DO}

The January issue of The $D O$ features a special series of articles on urban medicine-and how treatment modalities being developed in response to inner city problems may affect medicine in all areas. Topics include drug addiction among infants and mothers-to-be, treating victims of violence, the physician's role in improving community health, and an innovative osteopathic program aimed at teaching DOs about urban medicine.

Other articles in the January issue include a look at the new APA guidelines on benzodiazepine use and coverage of the recent AOHA meeting held in Monterey, Calif.

\section{JAOA}

- Wound complications following modified radical mastectomy: An analysis of perioperative factors

- Risk factors of nosocomial bacteremia associated with pulmonary artery catheters in a critical care unit

- Psychiatric aspects of chronic disease in adolescence

- Facilitated positional release

- Radiologic appearance of stress fractures

- Human immunodeficiency virus disease training: A 'how to' guide

- General practice residency training and the osteopathic profession: Trends and issues for the $1990 \mathrm{~s}$

- Transhiatal blunt esophagectomy for carcinoma of the esophagus

- Quality assurance monitoring of osteopathic manipulative treatment

- War, politics, and osteopathic medicine

- Is schizophrenia genetically transmitted? 


\section{ANAPROX DS.}

rellef for poin
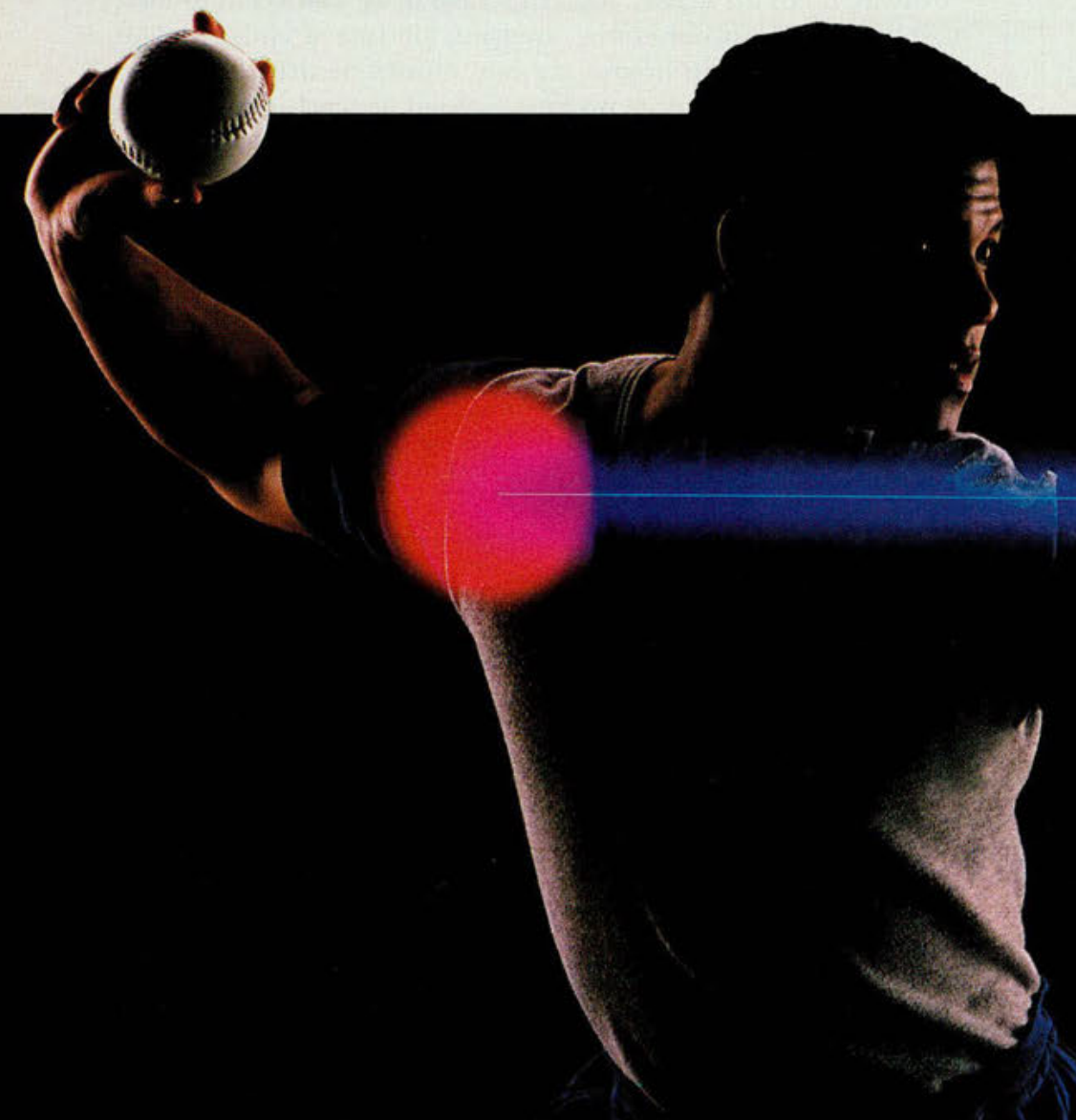

drome of asthma, minitis, and nasal polyps. Because anaphylactic reactions usually occur in patients with a history of such reactions, question patients for asthma, nasal polyps, urticaria, and hypotension associated with NSAIDs before starting therapy. If such symptoms occur, discontinue the drug. Warnings: Serious Gl toxicity such as bleeding ulceration, and perforation, can occur at any time, with or without waming symptoms, in patients treated chronically with NSAIDs. Remain alert for ulceration and bleeding even in the absence of previous GI tract symptoms. In clinical trials, symptomatic upper $\mathrm{G}$ uicers, gross bleeding or perforation occur in about $1 \%$ of patients treated for 3-6 months, and in about 2-4\% of patients treated for one year. Inform patients of signs and/or symptoms of serious GI toxicity and what steps to take If they occur.

Studies have not identified any subset of patients not at risk of developing pep tic ulceration and bleeding. Except for a prior history of serious Gl events and other risk factors associated with peptic ulcer disease, such as alcoholism smoking, etc., no risk factors (e.g. age, sex) have been associated with increased risk. Elderly or debilitated patients seem to tolerate ulceration or bleeding less well and most spontaneous reports of fatal Gl events are in this population. In considering the use of relatively large doses (within the recommended dosage rangel, sufficient benefit should be anticipated to offset the

potential increased risk of GI toxicity AMAPROX 0 R ANAPROX ${ }^{\circ}$ DS (NAPROXEN SODIUMO SINCE THEY CIRCULATE IN PLASMA AS THE NAPROXEN ANION. Acute interstitial nephritis with hemat ria, proteinuria, and nephrotic syndrome has been reported. Patients with mpaired renal function, heart failure, liver dysfunction, patients taking diuretics, and the elderly are at greater risk of overt renal decompensation. If this occurs, discontinue the drug. Use with caution and monitor serum creatinine and/or creatinine clearance in patients with significantly impaired renal function. Use caution in patients with baseline creatinine clearance less than $20 \mathrm{~mL} /$ minute. Use the lowest effective dose in the elderly or in patients with chronic alcoholic liver disease or cirrhosis. Borderline elevations of liver tests may occur in up to $15 \%$ of patients. Elevations of SGPT or SGOT occurred in controlled trials in less than $1 \%$ of patients. Severe hepatic reactions, including jaundice and tatal hepatitis, have been reported rarely. If liver disease develops or if systemic manifestations occur (e.g., eosinophilia or rash), discontinue therapy. If steroid dosage is reduced or eliminated during therapy, do so slowly and ooserve patients closely for adverse effects, including adrenal insufficiency and exace bation of arthritis symptoms. Determine hemoglobin values periodically for patients with initial values of 10 grams or less who receive long-term therapy Peripheral edema has been reported. For patients with restricted sodium intake, note that each tablet contains approximately 25 or $50 \mathrm{mg}(1$ or $2 \mathrm{mEQ}$ ) sodium. Use with caution in patients with fluid retention, hypertension or heart failure. The drug may reduce fever and inflammation, diminishing their diagnostic value. Conduct ophthalmic studies if any change or disturbance in vision occurs. Information for Patients: Side effects can cause discomfort and, rarely, more serious side effects, such as GI bleeding, may result in hosp talization and even tatal outcomes. Physicians may wish to discuss with patients potential risks and benefits of NSAIDs, particularly when they are used for less serious conditions where treatment without NSAiDs may be accep. able. Patients should use caution for activities requiring alertness if they expe rience drowsiness, dizziness, vertigo or depression during therapy. Laboratory Tests: Because serious Gl tract ulceration and bleeding can occur withou warning symptoms, follow chronically treated patients and inform them of the importance of the follow-up. Orug interactions: Use caution when giving concomitantly with coumarin-type anticoagulants; a hydantoin, sulfonamide or sulfonylurea; furosemide, lithium; beta-blockers; probenecid; or methotrexate Drug/Laboratory Test Interactions: May decrease platelet agyregation and prolong bleeding time or increase urinary values for 17 -ketogenic steroids. Temporarily stop therapy for 72 hours before adrenal function tests. May inter fere with urinary assays of 5 HIIAA. Carcinogenesis: A 2year rat study showed no evidence of carcinogenicity. Pregnancy: Category B. Do not use during pre nancy unless clearly needed. Avoid use during late pregnancy. Mursing Motters: Avoid use. Pediatric Use: Single doses of $2.5-5 \mathrm{mg} / \mathrm{kg}$ (as naproxen suspension), with total daily dose not exceeding $15 \mathrm{mg} / \mathrm{kg} / \mathrm{day}$, are safe in children over 2 years of age.

Adverse Reactions: In a study, GI reactions were more frequent and severe in heumatoid arthritis patients on $1650 \mathrm{mg} /$ day naproxen sodium than in those on $825 \mathrm{mg} / \mathrm{day}$. In children with juvenile arthritis, rash and prolonged bleeding times were more frequent, GI and CNS reactions about the same, and other reactions less frequent than in adults. Incidence Greater Than $1 \%$, Probable Causal Relationship: GI: The most frequent complaints related to the GI tract: constipation," heartburn," abdominal pain," nausea," dyspepsia, diarrhea, stomatitis. CNS: headache," dizziness," drowsiness," light-headedness, vertigo Dermatologic: itching (pruritus)" skin eruptions," ecchymoses," sweating, pu. pura. Special Senses: tinnitus;" hearing disturbances, visual disturbances. Ca. diovascular: edema, oyspnea" palpitations. General: thirst. "Incidence of reported reaction $3 \%-9 \%$. Where unmarked, incidence less than $3 \%$. Inc dence Less Than 1\%: Probable Causal Relationship: Gl: abnormal liver function tests, colitis, GI bleeding and/or perforation, hematemesis, jaundice, melena, peptic ulceration with bleeding and/or perforation, vomiting. Renal: glomerular nephritis, hematuria, interstitial nephritis, nephrotic syndrome, renal disease Hematologic: agranulocytosis, eosinophilia, granulocytopenia, leukopenia, thrombocytopenia. CNS: depression, dream abnormalities, inability to concen (rate, insomnia, malaise, myalgia and muscle weakness. Dermatologic: alope cia, photosensitive dermatitis, skin rashes. Special Senses: hearing mpairment. Cardiovascular: congestive heart failure. Respiratory: eosinophilic pneumonitis. General: anaphylactoid reactions, menstrual disorders, pyrexia chills and fever). Causal Relationship Unknown: Hematologic: aplastic anemia hemolytic anemia CNS: cognitive dysfunction. Dermatologic: epidermal necrol. ysis, erythema multiforme, Stevens-Johnson syndrome, urticaria. Gl: non peptic Gl ulceration, ulcerative stomatitis. Cardiovascular: vasculitis. General: angioneurotic edema, hyperglycemia, hypoglycemia

Overdosage: May have drowsiness, heartbum, indigestion, nausea, vomiting Empty stomach and use usual supportive measures. In animals $0.5 \mathrm{~g} / \mathrm{kg}$ of act: vated charcoal reduced plasma levels of naproxen.

Dosage and Administration for Mild to Moderate Pain, Dysmenorrhea and Acute Tendinitis and Bursitis: Recommended starting dose is $550 \mathrm{mg}$. fol lowed by $275 \mathrm{mg}$ every 6 to 8 hours. Total daily dose should not exceed $1375 \mathrm{mg}$ Dosage and Administration for Rheumatoid Arthritis. Osteoarthritis and Ankylosing Spondylitis: Recommended dose in adults is $275 \mathrm{mg}$ or $550 \mathrm{mg}$ twice daily. In patients who tolerate lower doses well, the dose may be increased to $1650 \mathrm{mg}$ per day for limited periods when a higher level of anti-inflammatory analgesic activity is required. At this dosage, physicians should observe suff: cient increased clinical benefits to offset potential increased risk. Caution: Federal law prohibits dispensing without prescription.

See package insert for full Prescribing Information. 132

THOMAS WESLEY ALLEN, D.o. Editor in Chief

\section{Long-term efficacy of danazol therapy in patients with autoimmune thrombocytopenia}

In a 6-year study, 96 patients with autoimmune thrombocytopenia were given danazol, either as initial or adjunctive therapy. Glucocorticoids were tapered gradually.

The overall response rate to danazol was $61.4 \%$. The platelet count (mean $\pm \mathrm{SD}$ ) among those who responded to this treatment was $36 \pm 24 \times 10^{9} / \mathrm{L}$ and $145 \pm$ $77 \times 10^{9} / \mathrm{L}$, respectively. Time to response was $2.7 \pm 3$ months.

Sex, age, and the absence or presence of a spleen influenced responses. Response rates improved with age in women only, particularly those with their spleens. The authors hypothesize that high estrogen levels in younger women may be a contributing factor in response rates.

When given for more than 1 year, danazol induced remissions lasting for years, even after the drug was discontinued. However, early relapses were frequent when danazol was administered for less than 6 months. Plate-associated IgG returned to normal range during unmaintained remission.

Based on these findings, the authors conclude that danazol is a good alternative to splenectomy in elderly patients, especially women.

Ahn YS, Rocha R, Mylvaganam R, et al: Long-term danazol therapy in autoimmune thromobcytopenia: Unmaintained remission and age-dependent response in women. Ann Intern Med 1989;111:723-729.

\section{Limitations of extracorporeal shockwave lithotripsy of gallstones}

Although no significant adverse effects of extracorporeal shockwave lithotripsy (ESWL) of gallbladder stones have been observed in animals-except for lung damage-long-term results in humans remain unknown. Clinical use of ESWL of gallbladder stones is confined to $15 \%$ to $30 \%$ of symptomatic patients. To achieve complete stone clearance, ESWL of gallbladder stones must be supplemented with adjuvant therapy. ESWL of bile duct stones is highly effective and can be considered in patients in whom primary endoscopic or surgical stone removal fails.

Second-generation lithotriptors permit outpatient treatments, but the clinical experience with most of the ESWL devices remains limited. The likelihood of gallbladder stone recurrence is a major disadvantage of ESWL treatment. A promising treatment modality for cholelithiasis, ESWL provides good short-term results. Long-term efficacy has yet to be ascertained.

Vergunst H, Terpstra OT, Brakel K, et al: Extracorporeal shockwave lithotripsy of gallstones: Possibilities and limitations. Ann Surg 1989;210:565-573.

\section{Monitoring prothrombin time at home}

Forty-six outpatients, recently started on warfarin therapy, participated in this randomized, pro-

(continued on page 504) 